\title{
Set-Based Design and the Ship to Shore Connector
}

Walter l. Mebane, Craig M. Carlson, Chris Dowd, David J. Singer, and Michael E. Buckley

\begin{abstract}
The Ship to Shore Connector (SSC), a replacement for the Landing Craft, Air Cushion (LCAC), is the first government-led design of a ship in over 15 years. This paper will discuss the changes that a government-led design presents to the design approach, including schedule, organization structure, and design methodology. While presenting challenges, a government-led design also afforded the opportunity to implement a new technique for assessing various systems and ship alternatives, setbased design (SBD). The necessity for implementing SBD was the desire to design SSC from a blank sheet of paper and the need for a replacement craft in a short time frame. That is, the LCACs need to be replaced and consequently the preliminary design phase of the SSC program will only be 12 months. This paper will describe SBD and how it was applied to the SSC, the challenges that the program faced, and an assessment of the new methodology, along with recommendations that future design programs should consider when adopting this approach.
\end{abstract}

\section{Ship to Shore Connector (SSC) Program BACKGROUND}

On November 28, 2007, Vice Admiral Paul Sullivan, Commander of the Naval Sea Systems Command (NAVSEA), met with Deputy Assistant Secretary of the Navy (DASN) SHIPs and Program Executive Office (PEO) SHIPs and agreed to allow the Ship to Shore Connector (SSC) Program to begin a government-led preliminary design (PD) and contract design (CD). The decision allowed the Navy to return to an approach, which they had not implemented during PD and CD in over 15 years. In previous inhouse Navy designs, NAVSEA used the traditional point-based design philosophy during PD. Because of NAVSEA's desire to complete both $\mathrm{PD}$ and $\mathrm{CD}$ within an extremely aggressive schedule of $<3$ years, senior management decided to pursue a different approach that would speed the process for analyzing craft and systems alternatives early in the design and also allow consideration of more of these alternatives. This approach involved the application of set-based design (SBD) at the start of PD.

In support of senior Navy management's decision to return to in-house ship design practices, SSC Design Team Management, and the Amphibious Warfare Program Office, PMS377, assembled a design team comprised of Subject Matter Experts to begin the task of implementing SBD.

SBD has been used in the automotive industry by Toyota but is relatively new to the ship design community (Singer et al. 2009). The first application of the SBD to a US Navy design is on the SSC. SBD primarily involves successive screening of design factors and options to discover those design factors and options that are most important to optimized design. Once the screening process is complete the result is a smaller set 
of potential designs, which subsequently allow designers to evaluate and analyze the remaining trade space of feasible designs in ever-increasing engineering detail until a best solution or family of solutions is developed. As the design process continues the designers may revisit decisions previously made in the trade space if requirements changes are warranted.

As described by Bernstein (1998), SBD preserves design flexibility through three basic tenets:

understand the design space, integrate by intersection, - establish feasibility before commitment.

The SSC design faced several challenges to implement SBD. Most notably, a very young, inexperienced team of engineers from the Naval Warfare Centers who would be responsible for leading the system development effort. The lead systems engineers were called Systems Engineering Managers (SEMs).

Toyota, the Japanese automobile manufacturer, had successfully implemented SBD to satisfactorily produce automobile designs in less time than their competitors (Ward et al. 1995). The SSC Design Team sought the expertise of Dr. David Singer, University of Michigan, who has conducted extensive research on the use of SBD for ship design, to act as an advisor and consultant before and during the PD and CD phases of design (Singer 2003). By implementing SBD, the SSC Design Team successfully designed a converged craft while meeting a demanding design schedule, completing the PD Phase of the SSC program within 12 months while considering a far larger number of alternatives than in a traditional point-based design evolution.

\section{GENESIS OF SSC REQUIREMENTS}

The SSC is the next generation Air Cushion Vehicle (ACV) that is planned as a replacement for the current fleet of Landing Craft, Air Cushion (LCAC), which have been in service since 1984. LCAC concept design began in the 1970s and resulted in full-scale Amphibious Assault Land- ing Craft test vehicles. At the conclusion of the Advanced Development Stage, two prototypes were built to prove the feasibility of high-density hovercraft for the Navy. The two craft, JEFF A and JEFF B, were built by Aerojet General and Bell Aerospace, respectively. The Navy eventually selected JEFF B, which subsequently became the design basis for the LCAC. From 1984 through 2000, a total of $91 \mathrm{craft}$ were delivered to the Navy. Textron Marine and Land Systems in New Orleans built $76 \mathrm{craft}$ and Avondale Gulfport Marine in Gulfport, Mississippi built 15 craft. The last LCAC delivered to the Navy was LCAC 91, which served as the basis for the LCAC Service Life Extension Program (SLEP) and was designed and built with the LCAC SLEP improvements installed during construction.

The SSC's mission is similar to the current inservice LCAC, to transport joint forces and equipment and ensure the Navy continues to possess a high-speed, over-the-beach, landing craft in the conduct of operations launched from the sea base within Operational Maneuver from the Sea. The SSC will transport equipment, personnel, and cargo from ships located over the horizon, through the surf zone, to landing points beyond the high water mark in a variety of environmental conditions.

The current fleet of LCACs begins phasing out of service in 2015. The LCACs have been the workhorse for carrying forces and supplies ashore during amphibious operations, but have become a significant consumer of operating force funds due to an increasing maintenance burden, aging technology, and obsolescence.

Today there are 79 LCACs in operation at Assault Craft Unit (ACU) 4 (Little Creek, Norfolk, VA) and ACU 5 (Camp Pendleton, CA). The LCAC is designed to transport weapon systems, including United States Marine Corps equipment, in addition to cargo and personnel from Navy amphibious ships via the well deck to the beach and beyond. LCACs were designed for a 20-year service life, to carry a design payload of 
up to 60 short tons (i.e., an M60 tank), at 35 knots, in a Sea State 3, from 15 nautical miles offshore, and are capable of operating independent of tides, water depth, underwater obstacles, ice, mud, or beach gradient. As tank designs progressed, the M60 tank was replaced with the M1A1 Abrams tank, which currently weighs 72 short tons with an additional 2 short tons for the Track Width Mine Plow (TWMP). Because of naval architectural safety operating limits, LCACs require an operational waiver and must sacrifice fuel capacity and thus range in order to operate in an overload condition (i.e., in order to carry an M1A1 tank with TWMP). SSCs were designed for a 30-year service life, to carry a design payload of up to 74 short tons in a nonoverload condition, at 35 knots, in a Sea State 3, from 25 nautical miles offshore, and are capable of operating independent of tides, water depth, underwater obstacles, ice, mud, or beach gradient. Interoperability constraints require the SSCs to enter and exit the well decks of existing amphibious ships (e.g., LPD, LSD, and LHD).

To address the concerns of aging craft, the Navy began the LCAC SLEP to add an additional 10 years to the craft service life. Initially the LCAC SLEP replaced the buoyancy box (hull) of the first $11 \mathrm{craft}$ along with refurbished rotating machinery, upgraded the Command, Control, Communications, Computers, and Navigation (C4N) System, enhanced the prime mover gas turbine engines, and implemented a new skirt design, the Deep Skirt. Analysis revealed additional cost savings by refurbishing vice replacing remaining craft buoyancy boxes.

The SSC Program began with studies and analysis in 2005. The Initial Capabilities Document (ICD) and Analysis of Alternatives (AoA) were approved in 2006 and 2007, respectively.

\section{NEW ACQUISITION AND DESIGN PROCESS CHALLENGES}

The decision to pursue a government-led design was based on several factors. There were a small number of first or second tier shipyards in the United States Industrial Base with ACV design expertise, so competition would likely be limited if these yards were to develop the design. The Navy had more experience with ACV technology, in particular over 20 years of operational experience with the LCAC program and LCAC SLEP. Lastly, based on recent contract experience there was concern on private industry's ability to meet a very time sensitive PD and CD schedule. Meeting an award date of FY 11 would mean completing and certifying the Technical Data Package (TDP) by the third-quarter of FY 10. Given this aggressive schedule the program was more likely to be successful with a government-led design. The SSC Design Team began PD in April 2008 with the goal of completing the PD Phase in 12 months. This aggressive schedule, along with additional acquisition process requirements, led the SSC Design Team to pursue a novel approach to design. One of the new acquisition process requirements that challenged the program was the implementation of the new 2 Pass 6 Gate process (see Figure 1).

The SSC Program had to make adjustments to the new 2008 requirements since the SSC AoA had been completed in November 2007, and had been approved by the Resources, Requirement Review Board (R3B) in December 2007. The R3B subsequently was allowed to be recorded as a successful Gate 2 review.

In preparation for the implementation of $\mathrm{SBD}$, the SSC Design Integration Team (DIT) developed an organizational structure based on the craft's key engineering disciplines, or system engineering areas. The DIT consisted primarily of the Ship Design Manager, the Deputy Ship Design Manager, and the Design Integration Manager. The Design Team was organized by systems engineering areas. These system engineering areas were each lead by a SEM and included the following areas: Auxiliary, C4N, Machinery, Hull, Human System Integration, and Performance. The Design Team was augmented by naval engineers in industry, including 


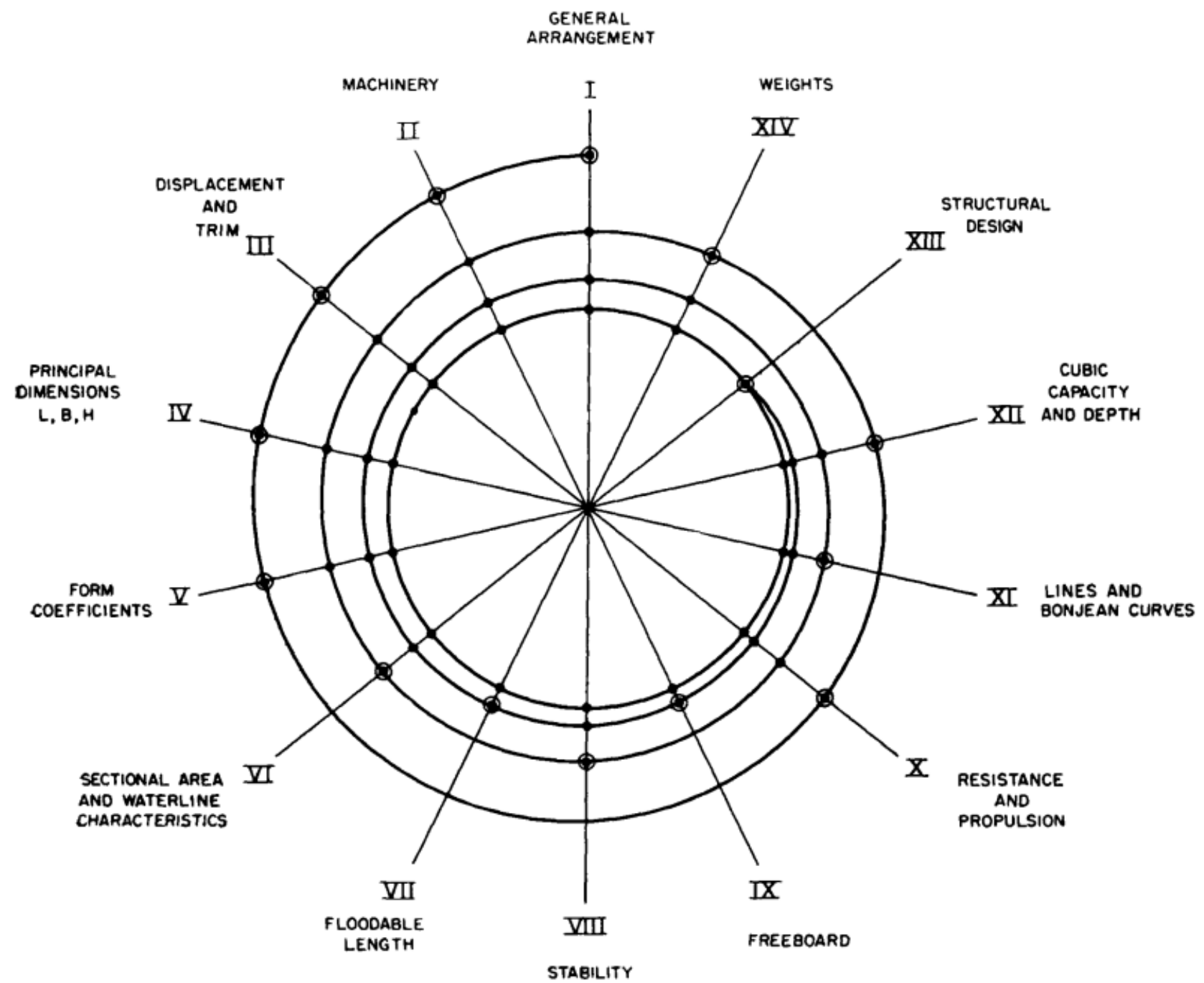

Figure 1: Navy 2 Pass 6 Gate Acquisition Process (Evans 1959)

one of the world's foremost ACV designers, CDI Marine-Band Lavis Division.

One of the first challenges to requirements development and traceability for SSC was that only a limited number of requirements were defined at the start of SBD. To overcome this, the SSC Design Team needed to further refine requirements based on standard practice, guidance from the Technical Warrant Holders, and insights gained from SBD analyses. All requirements needed to be documented for traceability, meaning that they were derived from a valid source document. Requirements that did not have a valid source document were captured as tentative requirements in the requirements tracking system until such time as they were formally validated. Upon approval by the DIT, the internal requirements documents were entered into the requirements traceability application, the Dynamic Object Oriented Requirements System (DOORS ${ }^{\circledR}$ ).

The Design Team used the ICD (approved October 18, 2006), the AoA Final Report (approved November 28, 2007), and the R3B 


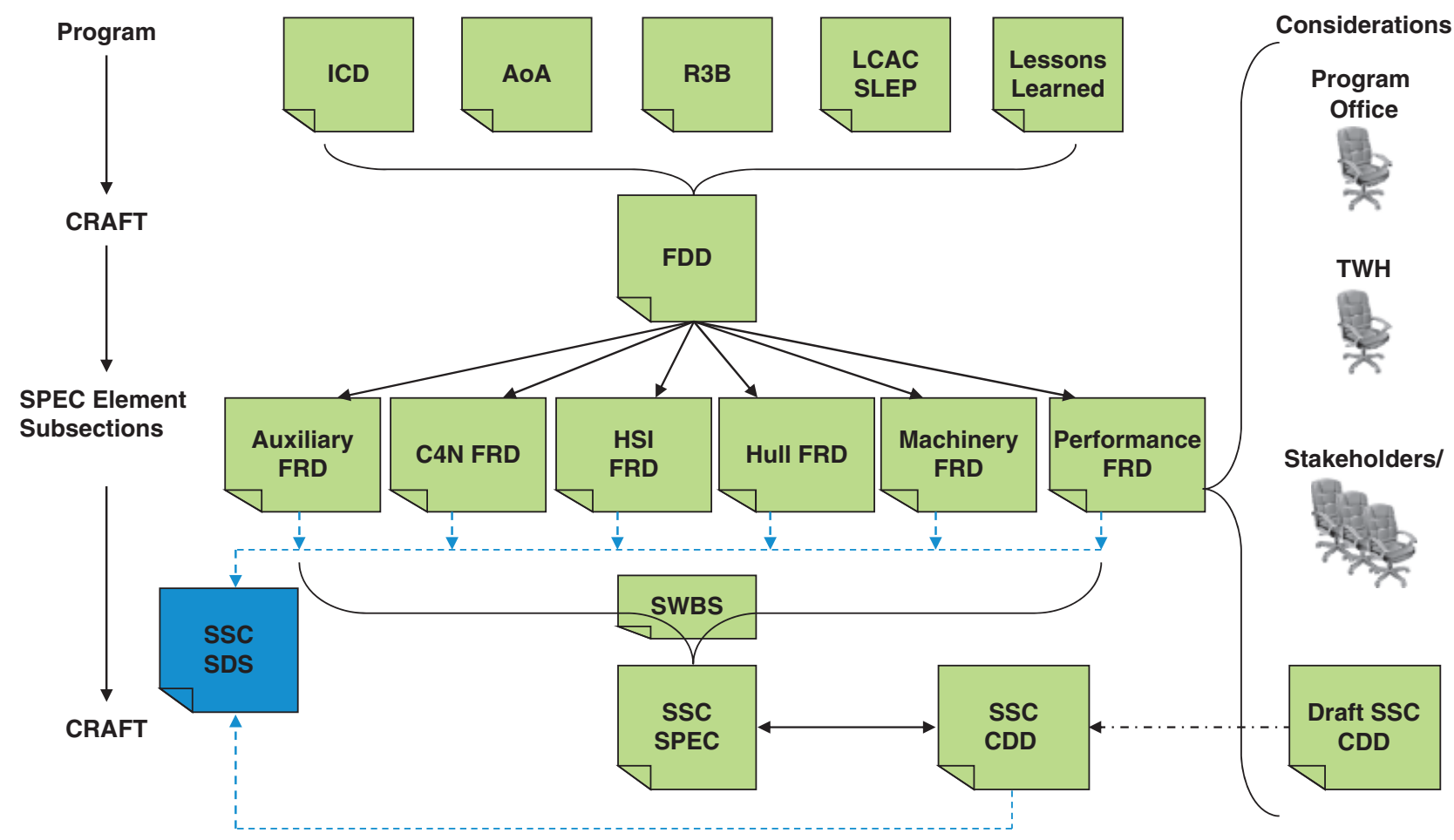

Figure 2: Ship to Shore Connector (SSC) Requirements to Specification Evolution

Decision Memorandum (approved January 4, 2008) as preliminary guidance to bound the craft's requirements while the Capabilities Development Document (CDD) was being developed. As shown in Figure 2, the SSC Design Team's approach was to use the ICD, AoA, R3B, as well as the LCAC specification, and lessons learned from LCAC operations as guidance to develop what the Design Team referred to as a Functional Design Document (FDD). The FDD was the set of operational requirements and derived parameters used to initiate the design effort. Using the FDD as the starting point, each SEM was required to develop a Functional Requirements Document (FRD) within their respective area. The FRD was an evolving set of assumptions and potential requirements that further defined the element trade space and ultimately constrained element-specific requirements. After initial craft-level design requirements were developed and approved by the DIT, the SSC Design Team began planning for PD and initiated the SBD effort. It should be noted that the requirements in the FDD and FRDs were subsequently mapped to their respective Ship Work Breakdown Structure (SWBS) area to become the draft specification for SSC.

Once the SSC requirements development process was established, the SSC DIT began preparation of the SSC PD Schedule, which included SBD, as shown in Figure 3. The SBD portion occurred before PD and was also referred to as prepreliminary design. Upon completion of trade studies associated with SBD, the DIT spent approximately 6 weeks integrating the various systems into the proposed baseline. This baseline was briefed to senior NAVSEA Technical representatives for concurrence and carried forward into PD.

PD incorporated two PD iterations (PD-1 and PD-2) and a period in which changes 


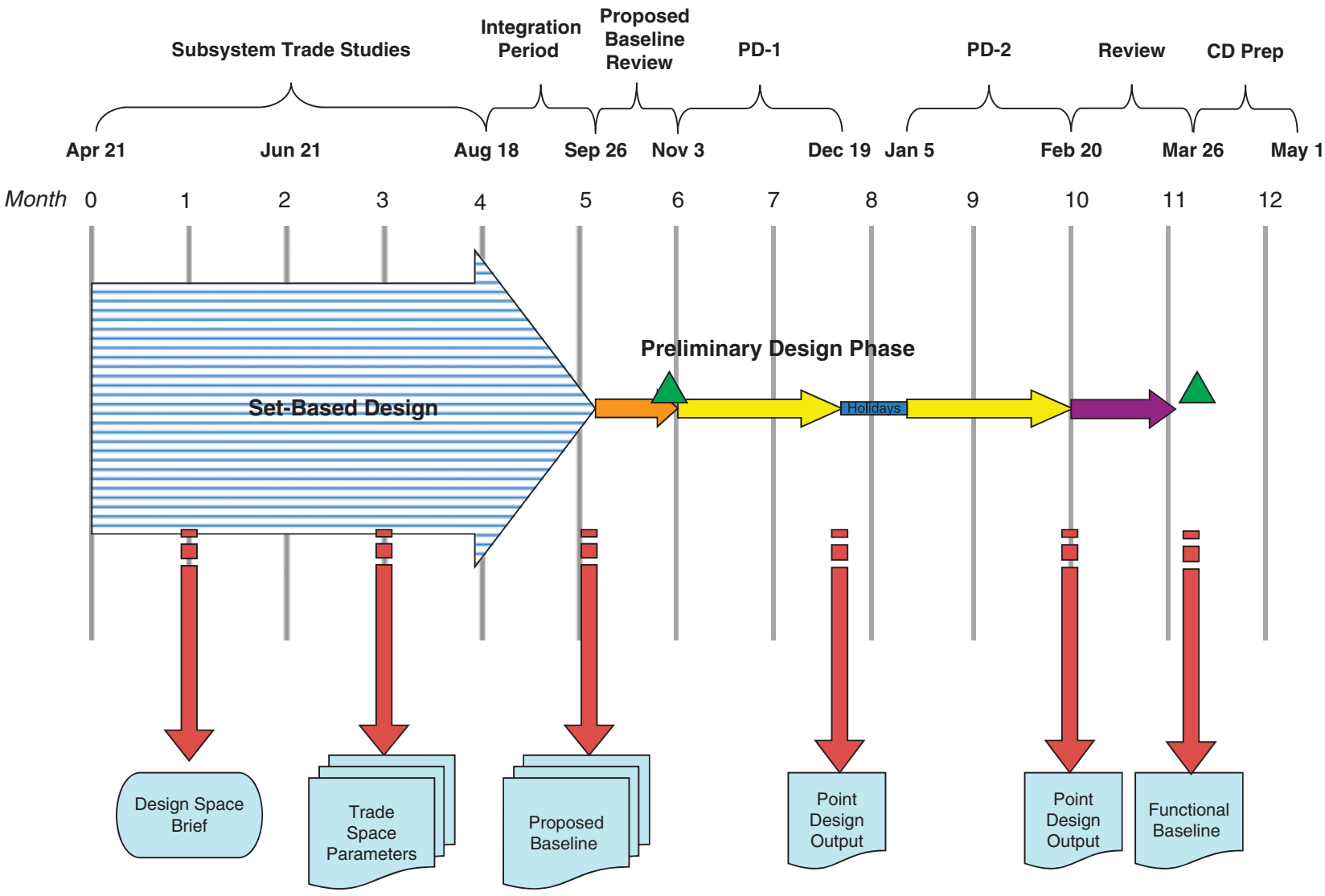

Figure 3: Ship to Shore Connector (SSC) Preliminary Design Schedule

resulting from model and analytical testing initiated during SBD could be incorporated. The PD-1 and PD-2 design phases were iterative developments lasting approximately 2 months each. The resulting baseline was briefed to senior NAVSEA Technical representatives for concurrence and carried forward into CD.

The resulting product at the end of PD and CD was a SSC TDP that consisted of a 112 section craft specification of over 700 pages, 32 contract drawings, and 6 Project Peculiar Documents. The craft specification was organized and assembled consistent with SWBS. Each specification section was approved and signed by its representative Technical Warrant Holder, and their respective senior management, or Deputy Warranting Officer.

\section{SBD AS APPLIED TO SSC}

Before the SSC design, all other navy ship designs have used the classic Design Spiral approach, as shown in Figure 4. Under this method, all design activities are accomplished in a particular order. Once each design cycle is complete, it is tested for design convergence and if not met, another cycle is repeated at a higher level of fidelity. Once convergence is achieved the design is further developed and refined.

In applying the SBD process to the SSC, the SEMs communicated ranges of solutions with associated derived requirements for various systems and performance levels rather than develop a single point solution. Figure 5 depicts how intersecting different ranges of solutions 


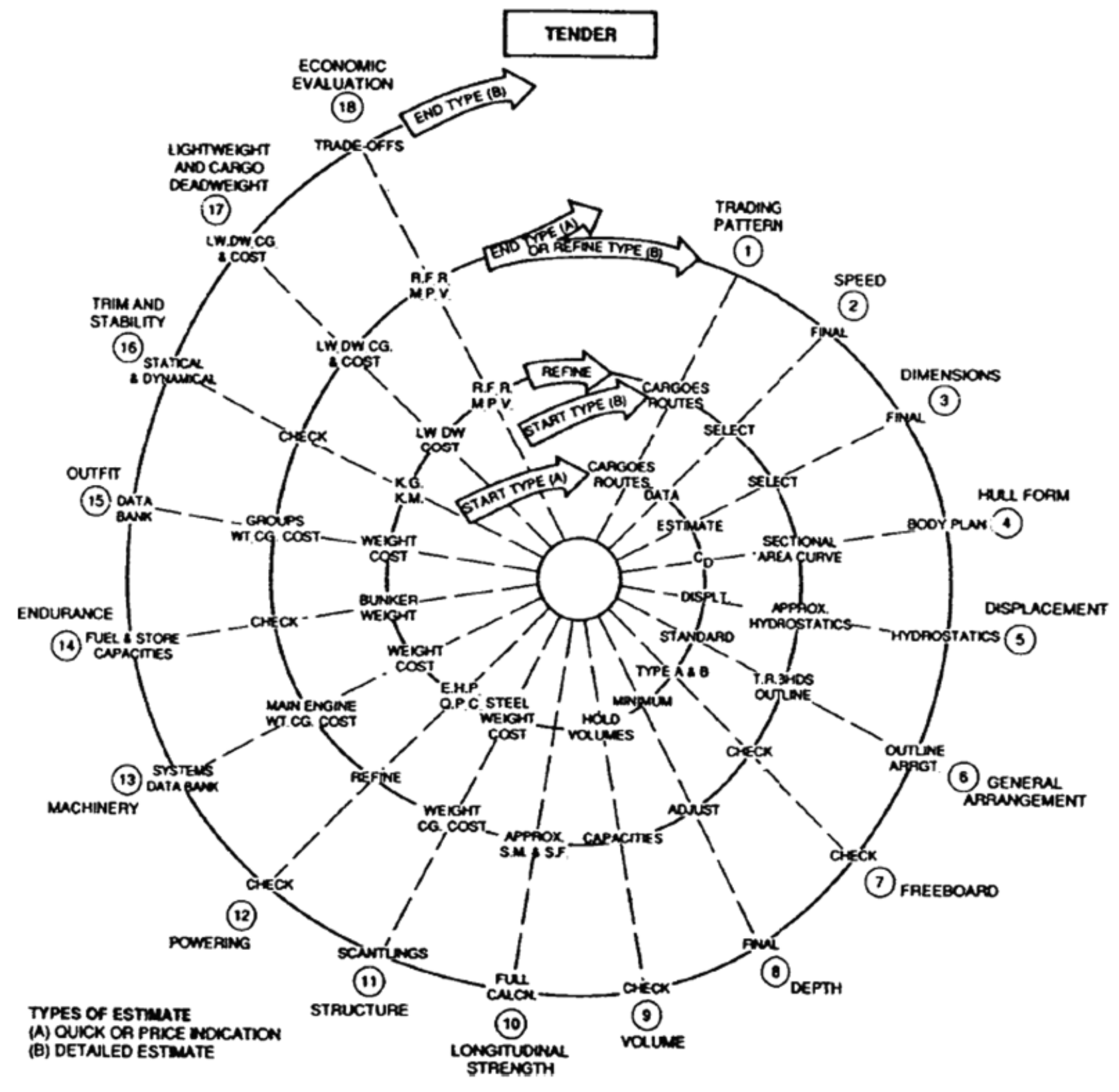

Figure 4: Classic Design Spiral

from different system engineering areas determined regions of feasibility. Examples of these regions include speed, length, or beam of the craft.

SBD execution was facilitated by the DIT staff. SEMs led their respective teams, continuously interfaced with each of the other SEMs, and reported to the DIT. Periodically, SEMs were tasked to filter out inferior or infeasible options in their respective design areas based on their team's design experience. The filtering was managed in a way that limited the risk of eliminating promising and feasible design options.

In assessing which approach would allow the SSC design to converge, the DIT decided not to pursue continuous function regression analysis 
Figure 5: Set-Based Design (Bernstein 1998)

(1)

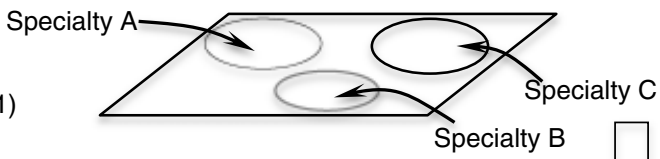

(2)

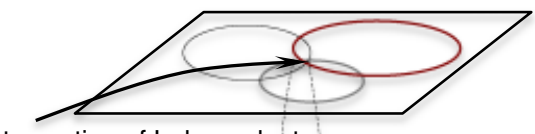

Intersection of Independent

Solutions

(3)

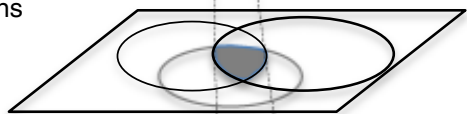

(4)

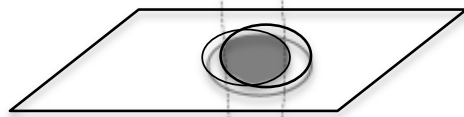

(5)

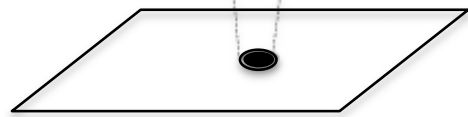

techniques at the craft level because the trade space was a complex mix of discrete choices and continuous ranges, making the approach intractable for the global screening within schedule constraints.
The SSC Design Team developed their schedule implementing SBD by dividing the process into three distinct steps-Trade Space Setup and Characterization, Trade Space Reduction, and Integration and Scoring (see Figure 6).

The first step in the SBD process for the SSC Design Team was Trade Space Setup and Characterization. This subsequently led to the development of Trade Space Summaries (TSSs). The TSSs were developed to include all that information required to characterize the element trade spaces, see Blocks (3), (4), (5), and (6) in Figure 6. Included in Trade Space Setup and Characterization was the incorporation of operational requirements, element specific attributes, and impacts resulting from interactions with Technical Warrant Holders, Block (9) in Figure 6. The TSSs served several functions: (1) Define/ Describe each element's trade space on a separate worksheet in the workbook; (2) Track progress in reducing each element's trade space; (3) Track progress in determining which craft-level

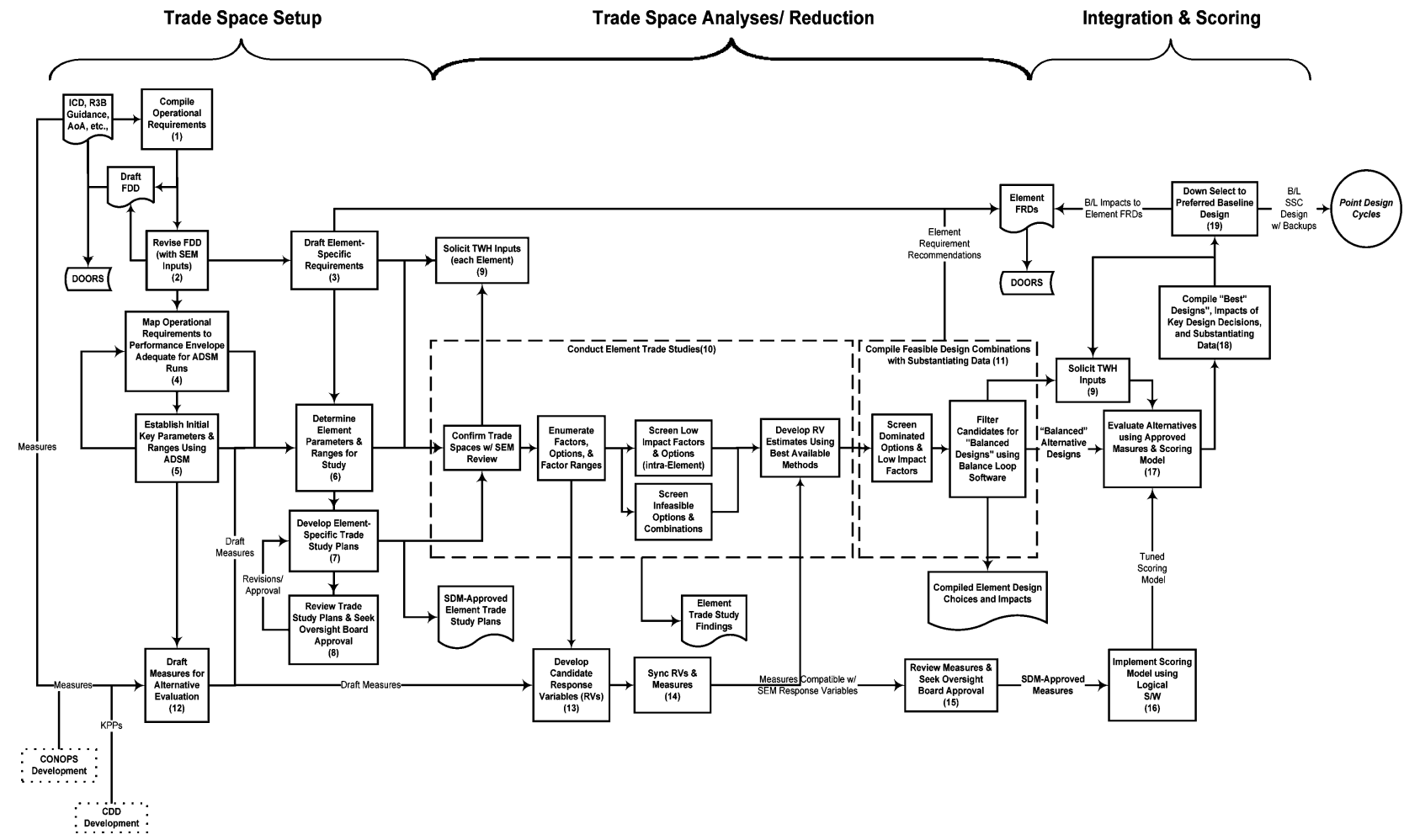

Figure 6: Set-Based Design Process Diagram with Numbered Processes 
attributes would contribute to the valuation of alternative craft designs; and (4) Standardize trade space descriptions across all elements.

The TSSs were used by the DIT to track progress during trade space reduction, and to assist in reviewing, tuning, and approving trade study plans, Blocks (7) and (8) in Figure 6. The objective of the TSSs was to provide a summary of all potential design parameters and ranges of the trade study and track them as element-specific summaries of the design parameters and their attributes during the set reductions. Each SEM developed a TSS for his systems that captured the essential parameters to properly investigate design options from the element's perspective. Once complete, the TSSs reflected a thorough review of each design parameter and a determination of potential significance at the craft level. In addition, all the parameter ranges of study and candidate options were identified. Throughout the Trade Space reduction, a constant discussion among the SEMs about their trade spaces was facilitated by the DIT.

TSSs were used to assist the SEMs and DIT to ensure that the output of the SEMs' regression analyses could support a robust evaluation of integrated designs.

The Trade Spaces were described by design parameters or factors, options or ranges of options (independent variables), and response variables (RVs). The RVs (dependent variables) represented attributes that registered value at the craft level.

Using the gearbox as an example, the Machinery SEM developed a TSS, which described the gearboxes as a design parameter or independent variable. For this parameter, under specific options or variable ranges of study, the SEM listed candidate numbers of gearboxes assessed in the trade studies that included propulsion drive trains with 2, 4, 6, 8, and 10 gearboxes. The Machinery SEM applied this approach to a host of design parameters, including: types of lift fans, candidate propulsors, bow thrusters, prime mover options, main engine type, quantities, and orientations. All SEMs applied this approach to their design parameters. The Auxiliaries SEM's design parameters included Fire Suppression Systems, HVAC Systems, Fuel Pumps, and Control Actuators.

The "RVs" for the design parameter "gearboxes" included Weight, Reliability, Cost, and Footprint. For the design parameter "Main Engine Quantity," RVs included Costs, Reliability, Availability, Excess Power, Footprint, Height, and Weight.

The second step in the SBD process as it applied to the SSC Program was Element Trade Space Analysis and Reduction (see Figure 6). Once the risks, traceability to requirements documents and trade space boundary criteria were developed, the Design Team examined multiple alternatives within each SEM area to arrive at acceptable intersections of feasible sets. The Design Team also identified a number of concepts that spanned a range of attributes (potential requirements). To seek convergence in the range of designs, each SEM conducted key trade studies that eventually led to the selection and location of major equipment and functions.

The SBD process as implemented included a systematic bounding of the trade space, developing measures of effectiveness, paring down alternatives, performing the analysis needed to identify feasible, and nondominated system and component alternatives. The key tools used while executing SBD included a wide range of analysis and data management tools. In many cases, the tools were specific to the subsystem analysis being performed as well as the analyst performing the work.

Several SEMs used statistical analysis software tools in Design of Experiments (DOE). DOE is a statistics-based procedure that implements a number of simulation runs and tests to characterize system/component performance under a wide variety of conditions. The SEMs exported the data to plot and generate response surfaces to further investigate areas of the design space. 
They then used Pugh (1991) matrices during early exploration of the trade space to provide a means to compare several design concepts against an established datum. This approach allowed the SEMs to quickly and easily identify the most feasible alternatives.

In developing a SBD baseline design, the DIT assisted the SEMs in reducing their fields of element options by screening remaining design combinations, in search of nondominated solutions at the craft level. As the SEMs reduced their design space, they began concentrating their efforts on cost and risk impacts to the overall program. Their focus was on arriving at Pareto dominated solutions, which are solutions with superior performance at lower cost, which were carried forward. This concluded with a design, which valued in performance, cost, and risk. Screening rules allowed the SEMs to reduce the trade space based on: design parameter significance, comparison of discrete options within a given design parameter, and identification of dominated solutions based on specific options or ranges of options within a design parameter.

SEMs were allowed to relax the assigned performance and weight attribute ranges for their respective element based on their knowledge of available components, technologies, materials, and other factors that could offer benefit to the craft as a whole. This was done to avoid overconstraining the explored design space and missing potentially promising design solutions. The SEMs then converted the relaxed performance and weight craft-level attribute ranges into sets of options, subsystem and component sets, and subsystem attributes and attribute ranges that defined the extent of each element's trade space.

Afterwards, the SEMs conducted trade studies to develop and comparatively evaluate subsystem alternatives within their trade space and subsequently developed criteria to support the comparative evaluation of the subsystem alternatives. They also screened infeasible or dominated trade space options and developed a set of nondominated attribute ranges with the
DIT providing oversight. The trade space reduction efforts on the SSC can be described as two subefforts: (1) Factor/Option Screening and (2) Combination Screening. The Factor/Option Screening effort focused on screening whole design parameters and options or option sets, while the Combination Screening effort focused on screening specific combinations of options based on incompatibilities.

For comparative evaluation, "pseudo designs," or integrated, craft-level concepts were developed. They were called pseudo designs because they had yet to be tested for craft-level viability based on some simple, craft-level checks. These candidate configurations were then subjected to a Balance Loop check to ensure that the design candidates passed a first order test for craft viability.

The third and final segment of the SSC SBD effort was Integration and Scoring. The DIT was unsure which method would provide the program with the most effective (and timely) convergence result. At this point the trade space numbered approximately $10^{8}$ potential design options. The DIT was faced with deciding among four convergence options.

These options included: (1) a brute force method where specific infeasibilities were diligently sought, (2) the use of a design synthesis model, (3) a factor screening method based on multiple linear regression techniques, and (4) a method enlisting negotiating functions defining interactions among the design parameters. The DIT subsequently used a brute force method.

\section{BALANCE LOOP}

In trimming the trade space during the final step (Integration and Scoring), the number of combinations (largely driven by the remaining machinery [432] and hull [90] options) remaining after the screening of known dominated solutions approached 40,000 combinations. This was reduced to 10,368 when certain hull configurations were eliminated from further consideration due to cost and weight. However, 


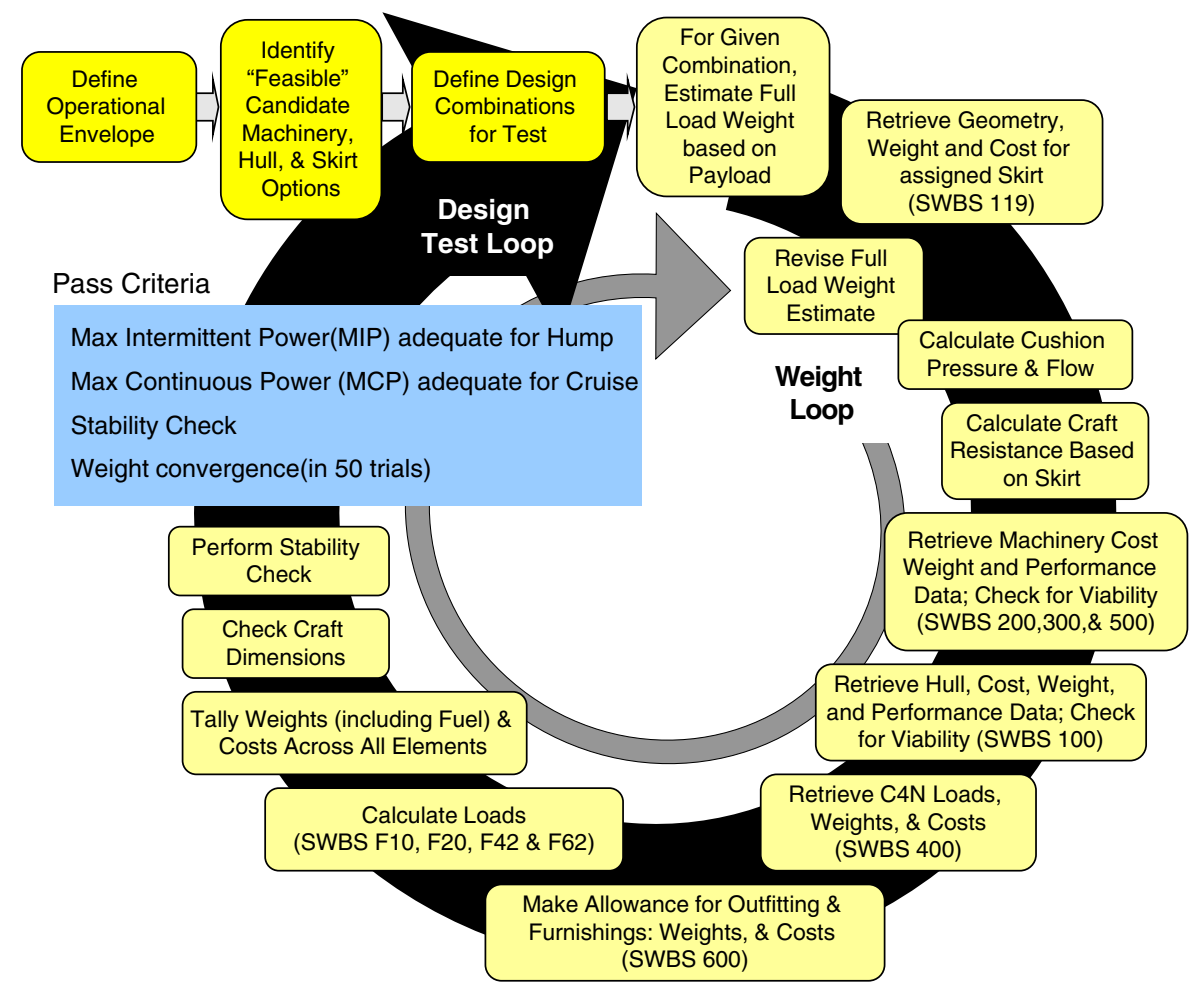

Figure 7: Diagram of the Balance Loop Process

the remaining 10,368 combinations needed to be evaluated for feasibility as physically viable craft. Looking at the combinations as potential craft design solutions, the DIT next used a useful and necessary first-order craft-level feasibility check. This tool was referred to as the Balance Loop (see Figure 7).

The Design Team used the Balance Loop to screen trade space combinations based on a first-order check for physical viability as an operating hovercraft. The Balance Loop included an initial stability check, a test for adequate power for the craft to get over hump, and a check for the craft's ability to maintain the required cruise speed. As a result of the Balance Loop check, the initial 10,368 options were reduced to 3,397 viable solutions for scoring. The Balance Loop operation identified viable Skirt, Machinery, Hull, and Auxiliaries combinations and tallied costs and weights, resulting in a converged fully loaded craft weight. The Balance Loop was successful in ensuring that (1) the major components of each design were balanced for weight and power; (2) the craft met a power-at- hump threshold; (3) fuel needs were accommodated; (4) the costs were tallied; and (5) the craft passed an empirical dynamic stability check.

After completion of the Balance Loop check, the results were verified through a five-step process that included: (1) verification of machinery architecture selection, (2) verification of hull architecture selection, (3) verification of variable assignment within Visual Basic code, (4) verification of cell assignments within worksheets, and (5) hand verification of the Balance Loop process.

The remaining 3,397 configurations were then comparatively evaluated in the measures considered most important for craft value. For this effort the DIT used a tool known as Logical Decision (LD) to score the remaining candidate configurations. LDs are commercially available decision analysis software. LD is founded on multiattribute utility principles. The LD Scoring Model was developed concurrently with the Balance Loop Software and built on the evolutionary effort begun at the beginning of 
Figure 8: Trade Space Reduction Over Time
Trade Space Reduction

(Progress from 05/07/08 to PD 1)

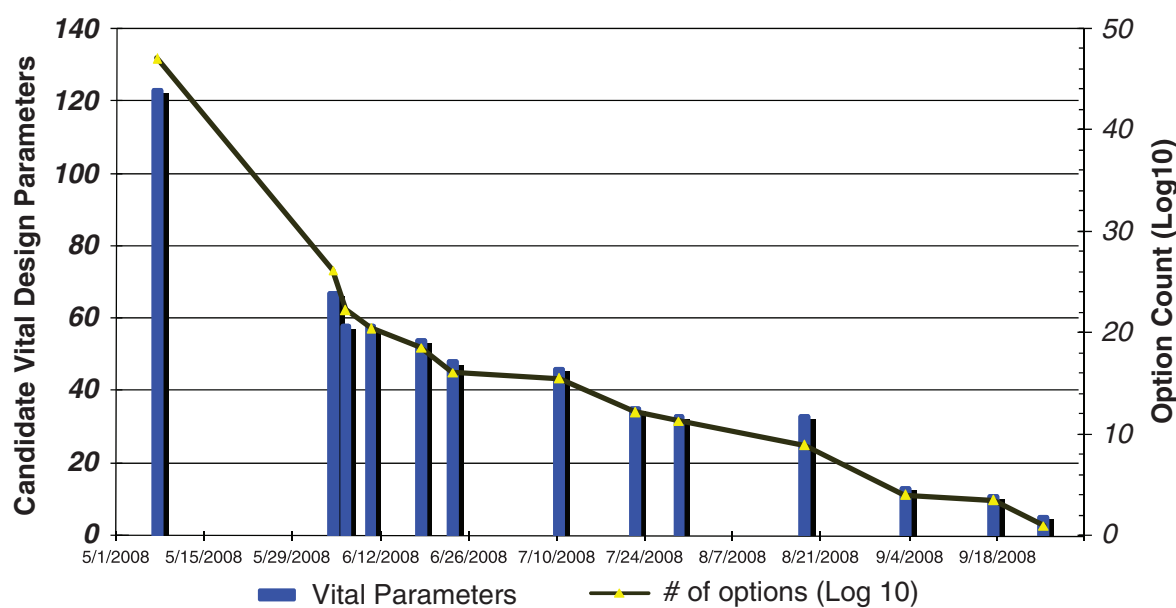

SBD to develop a sufficiently robust set of measures for craft-level scoring.

Candidate combinations remaining after the Balance Loop check were entered into an LD application specifically constructed using the RVs evolved during the SBD implementation. It was called the SSC LD Evaluation Model. The Balance Loop and SSC LD Evaluation Model were developed and verified concurrently, and results from the Balance Loop were fed into the LD Model in several passes. These iterations were necessary to work out data errors and anomalies. When the errors in the data stream settled out, the Balance Loop tallied 3,397 designs that passed the pass/fail criteria for viability. The 3,397 combinations were then compared in the LD Model. It is important to note that the Balance Loop was used at the end of the SBD process as a technical check for design feasibility. The Baseline itself did not drive the SBD process.

A total of 11 design parameters were used in the final comparison for craft-level value. These were the 11 design parameters used to differentiate the remaining candidate configurations. That is, the other design parameters did not impact the craft-level value such that the parameter would impact the craft-level configuration.
TRADE SPACE REDUCTIONS

Figure 8 depicts the rate of the trade space reduction over time, beginning early in May 2008. At that point, all SEMs had defined their trade spaces and it marked the formal start of the reduction effort.

Figure 8 looks across the trade space reduction effort, spanning all of the elements. At the start of the effort, we had over 120 design parameters and better than $10^{47}$ design combinations. At the beginning of the Integration on August 18, the lion's share of the reductions had occurred. However, at this point, there were still $10^{8}$ design combinations remaining. The DIT moved from focusing on design factor and option feasibility screening to screening infeasible or dominated combinations. Discarding the dominated solutions brought the tally to a little better than $10^{4}$ design combinations remaining. Then, the Balance Loop filter brought the tally to $<3,400$. Comparative evaluation with the LD Model confirmed the vital factors and options.

Using the results of LD scoring, tempered with subject matter expertise and judgment, two final configurations (one Aluminum Alloy craft and one Composite craft) were selected as Baselines for the SSC. 


\section{CONCLUSIONS}

The new acquisition and design process used on the SSC provided some unique insight into the challenges facing Navy Acquisition programs today. The first being requirements definition. Like most programs, early in the design timeline, requirements are generally broad and defined at a fairly high level. This causes problems for the systems engineers and designers because it is hard to develop and evaluate designs against a vague set of requirements. As an example, only the ICD was available at the start of PD, and it had only major craft-level requirements. An early version of the CDD was not available until the end of PD.

The SSC program's requirements development process allowed the systems engineer to define some of these detail requirements early, carry them as potential requirements until validated later by the CDD. This allowed the SBD process to go forward and permitted evaluation of an entire range of systems and craft alternatives in an orderly, structured manner. SBD offered the Navy an opportunity to examine a far greater range of options and alternatives than would have been considered in traditional point-based design evolutions and allowed this to be done in a much shorter time period. One shortcoming in the process was that cost estimates for many of the systems or craft alternatives could not be made because tools for assessing cost at this early stage are not available and only subjective reasoning could be used to assess this extremely important variable. The ability of the government engineers to once again develop designs in house was proven. The Navy's ability to develop a design with a distributed design team with much of the design team personnel remotely located in the field was certainly proven. The ability of competent but relatively inexperienced personnel to be trained quickly to develop effective designs is not only doable but offers hope that some of the SSC practices can be adapted to other ship design programs. It shows that despite the current staffing levels for engineers in NAVSEA, a core of experienced design engineers can be developed in the years ahead.
The SBD methodology offers great potential to naval ship design. The number of alternatives considered was impressive. The SSC, being an ACV, had some difficulty assessing design alternatives because the tools available were developed to assess ship concepts and system alternatives and is somewhat limited for assessing ACVs. For surface combatant or auxiliary ships, where there are more accredited synthesis tools, such as ASSET, evaluation of alternatives should be faster and easier. As the SBD methodology is expanded to other programs, a more uniform process for screening and paring down alternatives should be developed to accelerate evaluation and selection of the best systems for a particular mission.

\section{References}

Bernstein, J.I., "Design methods in the aerospace industry: looking for evidence of set-based practices." Master of Science thesis, Massachusetts Institute of Technology, 1998.

Evans, J.H., "Basic desiğn concepts," Naval Enģineers Journal, Vol. 21, pp. 671-678, November 1959.

Pugh, S., Total design: integrated methods for successful product development, Addison-Wesley, Wokingham, UK, 1991.

Secretary of the Navy (SECNAV), "Department of the Navy (DON) Requirements and Acquisition Process Improvement." SECNAVNOTE 5000 of February 26, 2008.

Secretary of the Navy (SECNAV), "Implementation and Operation of the Defense Acquisition System and the Joint Capabilities Integration and Development System." SECNAVINST 5000.2D of October 16, 2008.

Singer, D.J., "A hybrid agent approach for set-based conceptual ship design through the use of a fuzzy logic agent to facilitate communications and negotiation." Ph.D. dissertation, University of Michigan, 2003.

Singer, D.J., N. Doerry, and M.E. Buckley, "What Is SetBased Design?" Naval Engineers Journal, Vol. 121, No. 4, pp. 31-43, 2009.

Ward, A., J.K. Liker, J.J. Christiano, and D. Sobek II., "The second Toyota paradox: how delaying decisions can make better cars faster," Sloan Management Review, US, Vol. 36, pp. 43-61, 1995. 


\section{Huthor Biographies}

Walter L. Mebane is a Ship Design Manager (SDM) in the Future Concepts and Surface Ship Design Directorate at the Naval Sea Systems Command (NAVSEA) in Washington, DC. He is currently the SDM for the SSC Program. He has over 27 years of experience in ship design, systems engineering, and mechanical engineering on US Navy Combatant programs. Mr. Mebane was a 2010 recipient of the coveted Secretary of the Navy Safety Integration Acquisition Award. He is one of 160 Technical Warrant Holders (TWHs) within the NAVSEA Technical Authority chain of command and has been the TWH for Air Cushion Vehicles for the past 8 years. His educational background includes a Master of Engineering Management degree from The George Washington University (GWU) and undergraduate degrees from Hampton University and The George Washington University (B.S./ B.S.M.E). His professional affiliations include the American Society of Naval Engineers and the American Society of Mechanical Engineers.

Craig M. Carlson is the Ship to Shore Connector Deputy Ship Design Manager in the Future Concepts and Surface Ship Design Directorate at the Naval Sea Systems Command (NAVSEA) in Washington, DC. Previously, he was the Ship Concept Manager for the SSC Analysis of Alternatives. Before these positions, he has been in a number of positions in ship design, ship design practices and standards, computer-aided ship design, and project management at the Naval Sea Systems Command. Mr. Carlson has a B.S.E. and a M.S.E. degree in Naval Architecture and Marine Engineering from the University of Michigan, graduate studies at Johns Hopkins University, and is a graduate of the National Defense University Advanced Management Program.

Chris Dowd, P.E. is a Naval Architect in the Future Concepts and Surface Ship Design Directorate at the Naval Sea Systems Command (NAVSEA) in Washington, DC. He has over 13 years of experience in ship design, systems engineering, and marine engineering on US Navy programs and is currently the Design Integration
Manager (DIM) for the Ship to Shore Connector (SSC) Program. Chris earned a Master of Science degree in Systems Engineering from Virginia Polytechnic Institute and State University and a Bachelor of Science degree in Marine Engineering Systems from The United States Merchant Marine Academy (USMMA). He is the recipient of the District of Columbia Council of Engineering and Architectural Societies (DCCEAS) 2009 National Engineers Week Young Engineer of the Year Award, the Secretary of the Navy Safety Integration in Acquisition Award, and an AEGIS Excellence Award. He has served as the American Society of Naval Engineers (ASNE) Flagship Section Treasurer (four terms) and Vice Chairman (one term).

David J. Singer is an Assistant Research Scientist and Adjunct Assistant Professor in the Naval Architecture and Marine Engineering department at University of Michigan College of Engineering. He earned a B.S.E., M.Eng., and Ph.D. degrees in NA\&ME and a M.S.E. in Industrial and Operations Engineering from the University of Michigan. He conducts research in the areas of design theory, design optimization, and ship production. Dr. Singer won an ONR YIP award in 2007 for his work in Set-Based Design implementation using fuzzy logic.

Michael E. Buckley, B.S. Engineering Science, St. Mary's University' 76, is a systems engineer at Marine Design Dynamics Inc. (MDD), supporting the Navy's energy efficiency efforts for the Military Sealift Command (MSC). He also serves as a Set-Based Design consultant on the SAIC Team for DARPA's recently initiated ASW Continuous Trail Unmanned Vessel (ACTUV) Program. Before MDD, he was with CDI where he served as Process Engineer and Set-Based Design consultant on the Ship-to-Shore Connector Program, Originator of the Decision-Oriented System Engineering (DOSE) method, a patented process for a decision-oriented approach to the design of complex systems, he uses knowledgebased approaches in system and process design. Before CDI, he was with BMT Syntek Technologies and before that with the Naval Surface Warfare Center. He is a member of ASNE. 